Accelerator Department

BROOKHAVEN NATIONAL LABORATORY

Associated Universities, Inc.

Upton, L.I., N.Y.

AGS DIVISION TECHNICAL NOTE

No. 9

Th. S1uyters

November 30, 1965

STATUS REPORT (3) CONCERNING HIGH GRADIENT COLUMN AND

50 MEV FAST EMITTANCE DEVICE

\title{
Ion Source
}

During the shutdown, a duoplasmatron with small expansion cup $(\emptyset=4 \mathrm{~mm})$ has been installed in the present preinjector. After some minor technical difficulties, (e.g., cooling problems of magnet and housing of the palladium leak; we now use freon supplied from a cooling unit on the bottom of the pit via teflon tubes) this source supplies around $75 \mathrm{~mA}$ after the column and injected without loss into the 1inac. Focusing at the low energy end of the column is performed like the one used with the PIG source; the geometry of the extractor has been modified into a "Berkeley" shaped one (see Fig. 1). Though the source output current can be as high as $200 \mathrm{~mA}$, (see Status Report 2) upper limit of the present column plus pre-focusing system seems to be around $100 \mathrm{~mA}$. At the high energy end the gridded electrostatic lens has been removed to increase the beam brilliance. The emittance (area/ $\pi$ ) measured at $750 \mathrm{keV}$ is $8.7 \mathrm{~cm}$ mrad (brilliance around $1.5 \times 10^{8}$ ). A mean va lue of the PIG source (measured over June-July) is $.7 \times 10^{8 \%}$. With $30 \% \mathrm{H}_{2}^{+}$an acceleration efficiency was obtained of $60 \%$.

An important feature of beam alignment has to be mentioned; the beam from the column was misaligned with respect to the center of the transport system; alignment of the whole column improved the linac output with $20 \%$ which was not possible by optimizing with the steering coils.

We try to keep the duoplasmatron running in the present machine. There is a spare unit in the test rig, as well as a spare cathode stored and outgassing in a small vacuum chamber.

* One exceptiona 1 figure $1.6 \times 10^{8}$ of the PIG source was measured on October 1, 1965. 
The duoplasmatron with large cup ( $\geq \frac{1}{2}-i n$.) for the short column is assembled and it can be installed in the second test rig, which is now equipped with a mercury diffusion pump. Measurements on this source wi11 be made with the same basic equipment as used for the present operational source, so that brilliances can be compared.

\section{Accelerating Column}

Power, water supply, crane facility and shielding have been installed in the 905A Building; a smooth ceiling will be finished soon.

Assembling of the ceramic-aluminum inner pot of the column has started; mounting on its base, installation of vacuum equipment and leak checking can be expected during December.

A set (15) of divider resistances ("bananas") will be H.V. tested; production of another 15 bananas will start as soon as the first set is fu11-proof.

The spark gaps have been made. Gradients of a spark gap as a function of gap distances have been measured in air, in $\mathrm{SF}_{6}$ and in some combinations with $\mathrm{N}_{2}$. Some of the graphs are presented in Fig. 2 . Fluctuations in the gradients can be as high as $15 \%$; especially at short gap distances. From these results, we choose the gap distance for air .9-in. or $50 \mathrm{kV}$ breakdown voltage (running column up to $600 \mathrm{kV}$ or $40 \mathrm{kV}$ across the sparking gap). The gap distances for $\mathrm{SF}_{6}$ at 15 psia should be 5/16-in., corresponding with a breakdown voltage of around $70 \mathrm{kV}$ (running column up to $750 \mathrm{kV}$ or $50 \mathrm{kV}$ per section).

A11 parts for the measuring dome will be delivered before December 15 so that we can assemble the stack.

H.V.Supply (R.D.I.)

The R.D.I. has been removed to the 905A Building and first tests have been started.

Several parts have been repaired (toroidal coil, measuring resistances, rectifiers, etc.); the number of rectifier stages has been increased from 14 up to 16 so that higher voltages could be obtained; a1so the controls have been adapted to the new situation; $700 \mathrm{kV}$ has been reached for minutes; a rectifier caused failure; for several hours $500 \mathrm{kV}$ has been 
obtained; in genera1, failure starts in the rectifiers. R.D.I. suggests another tube with improved glass features because it believes that the trouble is caused by localized rf currents in the glass. Adequate cooling of the tubes is another possible improvement.

The group has started to assemble an adequate bushing from R.D.I. to load resistor, as well as from load resistor to dome, using the Sames unshielded cable.

Six-hundred $\mathrm{kV}$ should be available at the end of December. The inner part of the column (electrodes, rigging of inner electrodes, solenoid, photographic emittance device, Faraday cup and source) will be a11 available after January 15, so that after two months from now, the assembly can be checked at $500-600 \mathrm{kV}$ without the skirts (available in February 1966).

\section{$50 \mathrm{MeV}$ Emittance Device}

The emittance "box" can be assembled and equipped during the second part of December. Also, during this time, the controls can be installed.

cc: R. Amari

R. Damm

V. Kovarik

R. Lane

R. Larson

W. Livant

R. Lockey

A. Otis

V. Racanie11o

W. Schneider

A. van Steenbergen

H. Wroe 


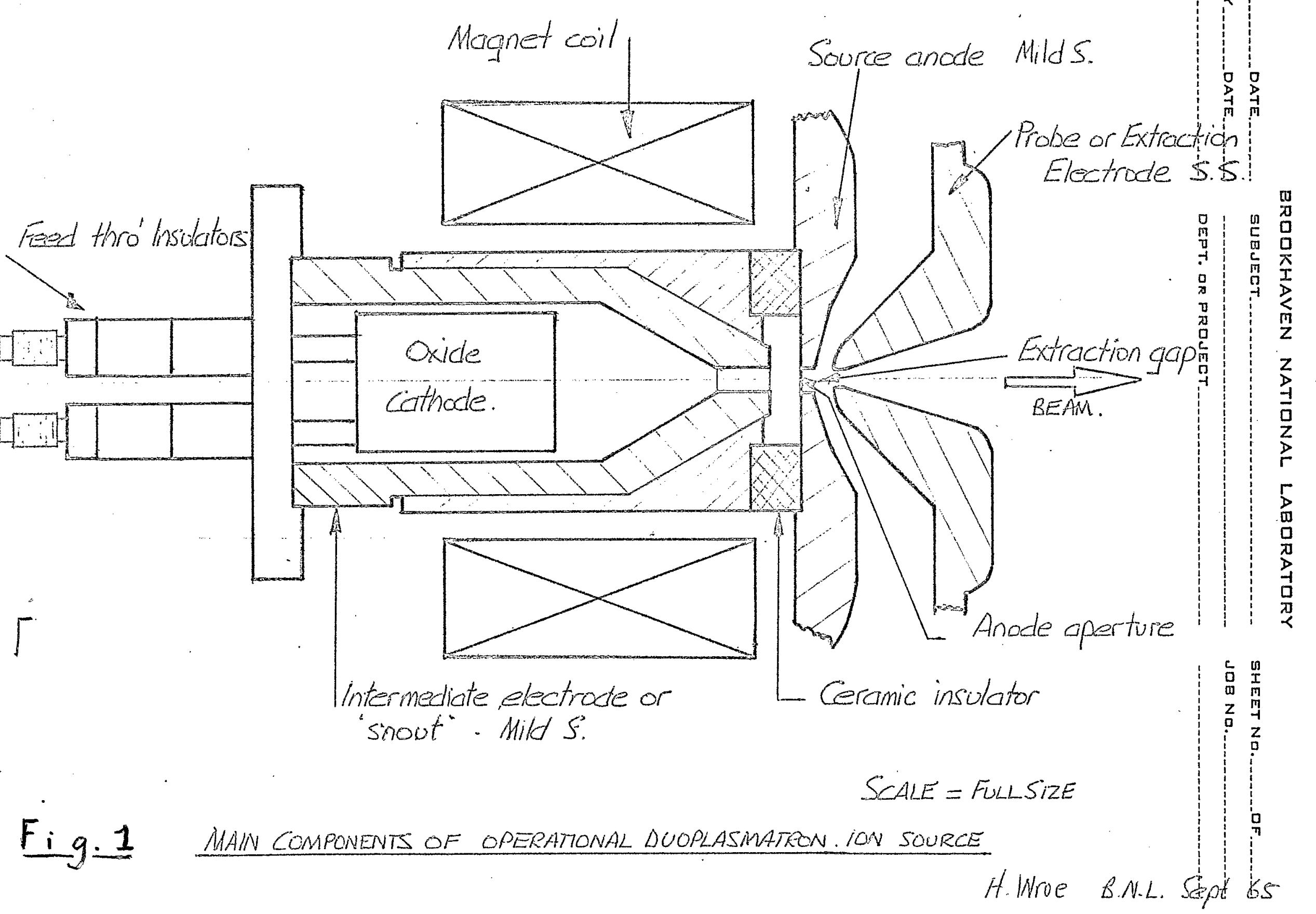




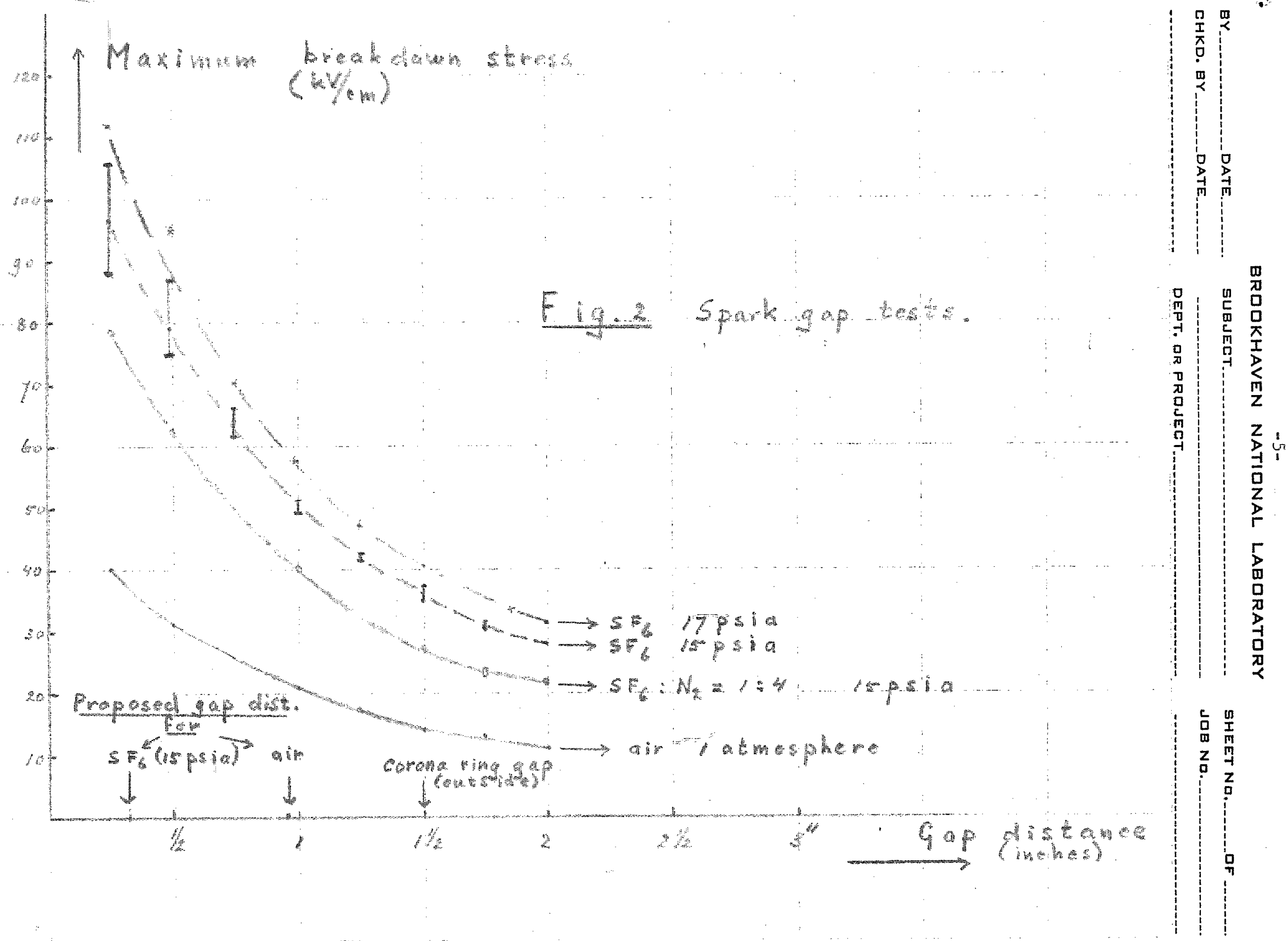

